\title{
Tricyclic flavonoids with 1,3-dithiolium substructure
}

\author{
Lucian G. Bahrin ${ }^{* 1,2}$, Peter G. Jones ${ }^{3}$ and Henning Hopf ${ }^{2}$
}

\section{Full Research Paper}

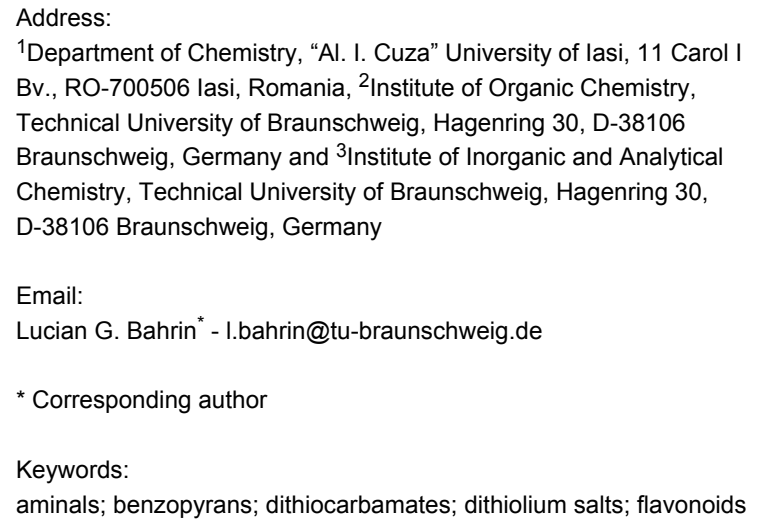

Beilstein J. Org. Chem. 2012, 8, 1999-2003.

doi:10.3762/bjoc.8.226

Received: 27 August 2012

Accepted: 18 October 2012

Published: 16 November 2012

Associate Editor: P. R. Hanson

(C) 2012 Bahrin et al; licensee Beilstein-Institut. License and terms: see end of document.

\begin{abstract}
The synthesis of new 3-dithiocarbamic flavonoids has been accomplished by the reaction of the corresponding 2-hydroxyaryl dithiocarbamates with aminals. These flavonoids were obtained as a mixture of diastereoisomers, the anti isomer being the major one. The heterocyclization of these compounds provided novel tricyclic flavonoids bearing a 1,3-dithiolium-2-yl ring fused at the 3,4-carbon positions of the benzopyran moiety.
\end{abstract}

\section{Introduction}

The great diversity in physical, chemical and biochemical properties of flavonoids gives them the ability to influence the biological activity of plants, microbes and animals [1-3] Flavonoids are known to be good antioxidants and this is believed to be the most probable mechanism of protection that these compounds offer against conditions such as cancer or cardiovascular disease [4].

SERBAs, or selective estrogen receptor $\beta$ agonists, are benzopyran derivatives that interact with estrogen receptor subtypes $\alpha$ and $\beta$. The interest in this type of compound led to the synthesis of derivative $\mathbf{1}$, a selective estrogen receptor $\beta$ agonist (SERBA-1, Figure 1) [5]. Studies that focus on the structure-activity relationship were reported [6,7]. It was shown that a cyclopentane ring at the 3,4-carbon positions (labeled C,
Figure 1) leads to a substantial rise in the binding affinity for estrogen receptor $\beta$. Further improvements in binding selectivity were obtained by combining the modifications performed on the $\mathrm{C}$ ring with modifications performed on the A ring, e.g. 2, Figure 1 [8].

Extracts from Hematoxylum campechianum and Caesalpinia sappan are known to be effective in the treatment of various conditions, such as diarrhea, dysentery, dyspepsia, leucorrhea, and diabetic complications $[9,10]$. The main components of $H$. campechianum and C. sappan are hematoxylin (3, Figure 1) and brazilin; the basic structures of the two contain a 3,4-cycloalkylfused benzopyran unit. In addition to this, they are known to possess anti-inflammatory activity, inhibit the lens-aldose reductase, and decrease the blood glucose level $[11,12]$. More- 


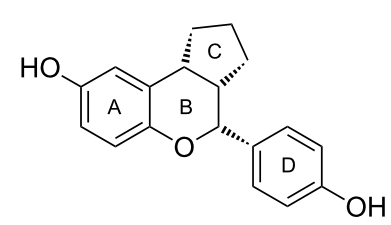

1, SERBA-1

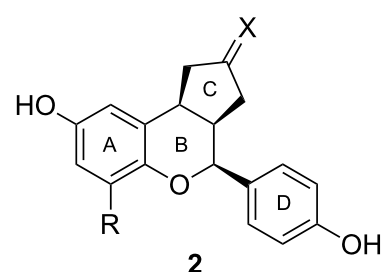

2

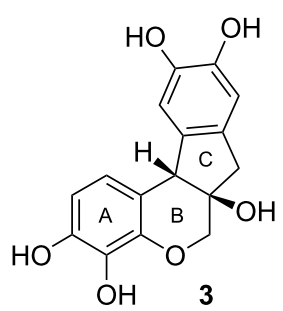

Figure 1: Polycyclic flavonoids.

over, compound 3 was shown to inhibit HIV-1 integrase $[13,14]$.

Several molybdenum and tungsten oxobisdithiolene complexes have been synthesized from a tricyclic flavonoid bearing a 1,3dithiolium-2-yl unit as $\mathbf{C}$ ring [15]. These complexes have been electrochemically investigated to provide a better understanding of enzymatic activities in thermophilic and hyperthermophilic organisms.

This paper outlines the synthesis of novel tricyclic flavonoids bearing a 1,3-dithiolium-2-yl ring fused at the 3,4-carbon posi- tions of the benzopyran moiety, utilizing the heterocyclization of corresponding 3-substituted dithiocarbamic flavonones.

\section{Results and Discussion}

The treatment of several dithiocarbamates of type $\mathbf{4}$ with aminals has been reported to provide new substituted flavanones and related 4-chromanones [16]. Based on this study, we decided to investigate the synthesis of new flavonoids bearing a 1,3-dithiolium-2-yl ring fused at the 3,4-carbon positions of the benzopyran core. The reaction of dithiocarbamates 4 with aminals $\mathbf{5}$ provided 3 -substituted dithiocarbamic flavanones $\mathbf{6}$ as a mixture of diastereoisomers (Scheme 1, Table 1). The analyt-<smiles>[R]c1ccc(C(N(CC=O)CCO)N(CCO)CCO)c(O)c1</smiles>

4<smiles>[R]c1ccc([C@H]2Oc3c([R])cc([R1])cc3C(=O)[C@H]2SC(=S)N([R])[R])cc1</smiles>

6<smiles></smiles>

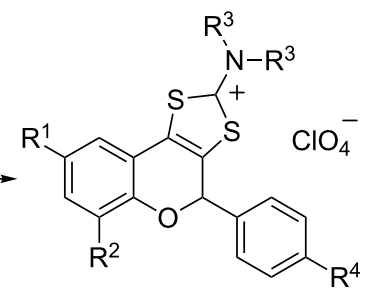

7

$\mathrm{HX}=\mathrm{H}_{2} \mathrm{SO}_{4} / \mathrm{AcOH} 1: 3$ or $\mathrm{P}_{2} \mathrm{O}_{5} / \mathrm{MeSO}_{3} \mathrm{H} 1: 10$

Scheme 1: The synthesis of flavonoids 6 and 7.

\section{Table 1: Flavonoids 6 and 7.}

\begin{tabular}{|c|c|c|c|c|c|c|}
\hline $6,7^{a}$ & $\mathrm{R}^{1}$ & $\mathrm{R}^{2}$ & $\mathrm{R}^{3}-\mathrm{N}-\mathrm{R}^{3}$ & $\mathrm{R}^{4}$ & Yields for 6, (\%) & Yields for $\mathbf{7},(\%)$ \\
\hline $\mathbf{a}$ & $\mathrm{H}$ & $\mathrm{H}$ & & $\mathrm{H}$ & 88 & 73 \\
\hline b & $\mathrm{H}$ & $\mathrm{H}$ & & OMe & 83 & 60 \\
\hline c & $\mathrm{H}$ & $\mathrm{H}$ & $\mathrm{NEt}_{2}$ & $\mathrm{OMe}$ & 60 & 76 \\
\hline d & $\mathrm{Br}$ & $\mathrm{H}$ & $\mathrm{NEt}_{2}$ & $\mathrm{Cl}$ & 71 & 71 \\
\hline e & $\mathrm{Br}$ & $\mathrm{H}$ & $\mathrm{NEt}_{2}$ & $\mathrm{H}$ & 81 & 64 \\
\hline f & $\mathrm{Br}$ & $\mathrm{Br}$ & $\mathrm{NEt}_{2}$ & $\mathrm{H}$ & 62 & 80 \\
\hline g & I & I & $\mathrm{NEt}_{2}$ & $\mathrm{H}$ & 64 & 80 \\
\hline h & 1 & I & $\mathrm{NEt}_{2}$ & $\mathrm{Cl}$ & 87 & 65 \\
\hline
\end{tabular}

a $7 \mathrm{~g}$ and $7 \mathrm{~h}$ prepared in the presence of $\mathrm{P}_{2} \mathrm{O}_{5} / \mathrm{MeSO}_{3} \mathrm{H}(1: 10)$ mixture. 
ical and spectroscopic data are in agreement with the structures. 2-Hydroxyphenacyl dithiocarbamates $\mathbf{4}$ are known compounds and were prepared following the reported experimental procedures [16-19]. Aminals 5 were synthesized according to the literature procedures $[20,21]$.

Although the original short synthetic communication on flavonoids of type 6 [16] did not mention the existence of diastereoisomers, we always identified an inseparable mixture of two diastereoisomers. Each isomer could be identified, however, by their different NMR chemical shifts and coupling constants of the H-2 and H-3 hydrogen atoms (6' and 6", Figure 2). Furthermore, a major isomer was identified for all flavonoids $\mathbf{6 a}-\mathbf{i}$. We therefore decided to investigate the structures of the two diastereoisomers, together with the influence of substituents on their ratio. In principle, the two isomers could have the hydrogen atoms at the 2 and 3 positions directed either to opposite sides or to the same side of the benzopyrane ring. The relative orientation of the two hydrogen atoms would, of course, be expected to have an influence on the magnitude of their coupling constants. Moreover, it is reasonable to assume that the most stable isomer is that with an anti orientation of the two hydrogen atoms (e.g., 6', Figure 2).<smiles>[R]c1cc([R])c2c(c1)C(=O)[C@H](SC(=S)N([R])[R])[C@@H]([AlH2])O2</smiles><smiles>[R]c1cc([R])c2c(c1)C(=O)[C@H](SC(=S)N([R])[R])[C@]([2H])([12Br])O2</smiles>

Figure 2: Diastereoisomers of flavonoids 6.

The coupling constants and diastereoisomeric ratios of flavonoids 6 are presented in Table 2. Data analysis indicates that the highest diastereoisomeric ratios are obtained for $\mathbf{6 a}$ and 6b, i.e., the flavonoids with an $\mathrm{N}$-morpholinyl carbodithioate substituent. Although no significant influence of the substituents on ${ }^{3} J_{\mathrm{H} 2-\mathrm{H} 3}$ coupling constants of syn isomers was recorded, an unexpected variation of the coupling constant with the $\mathrm{R}^{2}$ substituent was recorded for the anti isomers. The replacement of the hydrogen atom at $\mathrm{C} 8$ by a bulky bromine or iodine atom induces a decrease of the ${ }^{3} J_{\mathrm{H} 2-\mathrm{H} 3}$ coupling constant by about $2 \mathrm{~Hz}(\mathbf{6 f}-\mathbf{h})$.

The structural information provided by the NMR data has been unambiguously corroborated by X-ray analysis. The structures of the anti isomers of flavonoids $\mathbf{6 a}$ and $\mathbf{6} \mathbf{b}$ are presented in Figure 3 and Figure 4, respectively.

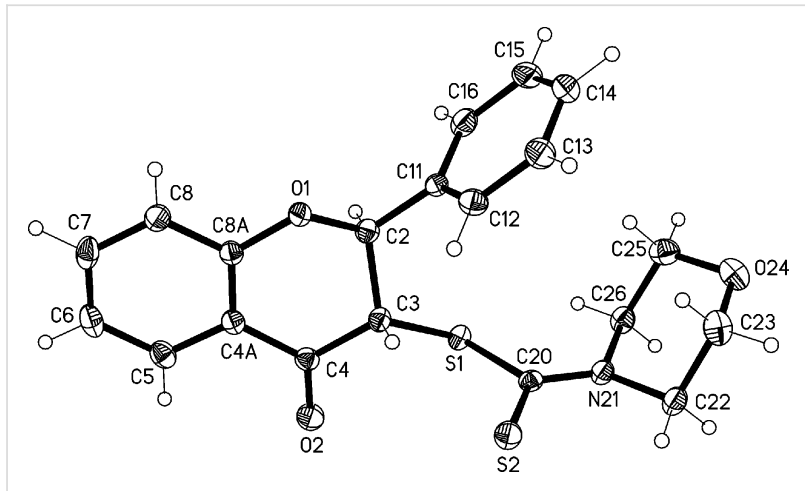

Figure 3: Molecular structure of flavonoid $\mathbf{6 a}$ in the solid state. Ellipsoids represent $50 \%$ probability levels. Torsion angle $C(11)-C(2)-C(3)-S(1):-59.19(14)^{\circ}$.

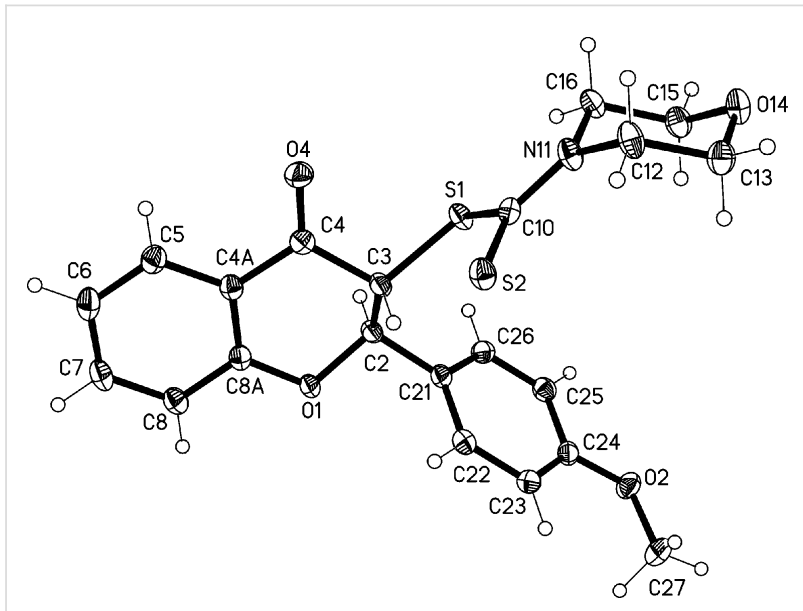

Figure 4: Molecular structure of flavonoid $\mathbf{6 b}$ in the solid state. Ellipsoids represent $50 \%$ probability levels. Torsion angle $\mathrm{C}(21)-\mathrm{C}(2)-\mathrm{C}(3)-\mathrm{S}(1): 59.72(11)^{\circ}$.

Table 2: Coupling constants and diastereoisomers ratio of flavonoids 6 .

\begin{tabular}{|c|c|c|c|c|c|c|c|c|}
\hline 6 & $\mathbf{a}$ & b & c & d & e & $\mathbf{f}$ & g & $\mathbf{h}$ \\
\hline${ }^{3} J_{\mathrm{H} 2-\mathrm{H} 3}$ anti $(\mathrm{Hz})$ & 9.3 & 9.8 & 9.3 & 9.5 & 9.5 & 7.6 & 7.2 & 7.8 \\
\hline${ }^{3} J_{\mathrm{H} 2-\mathrm{H} 3} \operatorname{syn}(\mathrm{Hz})$ & 4.0 & 4.3 & 4.3 & 4.0 & 4.2 & 4.0 & 4.1 & 3.8 \\
\hline anti/syn ratio & $86: 14$ & $77: 23$ & $73: 27$ & $72: 28$ & $69: 31$ & $65: 35$ & $64: 36$ & $69: 31$ \\
\hline
\end{tabular}


The main synthetic approach for various substituted 1,3-dithiolium-2-yl cations consists of the cyclization of phenacyl carbodithioates by using acid as catalyst. The heterocyclization of compounds 6 should, hence, provide new tricyclic fused flavonoids 7 by using an appropriate mixture of acids, as described above (Scheme 1, Table 1). Using a concentrated sulfuric acid/glacial acetic acid (1:3 v/v) mixture [22-24] the cyclization of dithiocarbamates $\mathbf{6 a}-\mathbf{f}$ takes place under mild reaction conditions. By heating the reaction mixture at $80{ }^{\circ} \mathrm{C}$ a homogeneous solution was obtained, which contains the corresponding 1,3-dithiolium ions. The addition of $70 \%$ perchloric acid to the cooled solution, followed by water yielded perchlorates $\mathbf{7 a - f}$, isolated as white crystalline products in good to excellent yields $(60-80 \%)$. Attempts to cyclize $N, N$-dialkyldithiocarbamates $\mathbf{6 g}$ and $\mathbf{6 h}$ by using the above-mentioned or other common cyclization agents, according to the literature [25-27], led to degradation of the substrates, often accompanied by loss of molecular iodine. A literature survey revealed that a $\mathrm{P}_{2} \mathrm{O}_{5} / \mathrm{CH}_{3} \mathrm{SO}_{3} \mathrm{H}(1: 10$, $\mathrm{m} / \mathrm{v}$ ) mixture may be the cyclization agent of choice to obtain 1,3-dithiolium salts $\mathbf{7 g}$ and $\mathbf{7 h}$ as pure compounds and in high yields $[28,29]$. Thus, a suspension of $\mathbf{6 g}$ or $\mathbf{6 h}$ in three parts of the "superacid" mixture was stirred at room temperature for $30 \mathrm{~min}$ to give a solution that contained the corresponding 1,3-dithiolium cation. Addition of $70 \%$ perchloric acid and methyl acetate to this solution yielded perchlorates $7 \mathbf{g}$ and $\mathbf{7 h}$ as white crystalline products in $65-80 \%$ isolated yield.

The structure of these charged tricyclic fused flavonoids was unambiguously proved by X-ray analysis. The structure of tricyclic flavonoid cation 7a is presented in Figure 5. Structures of the perchlorate salts proved to be disordered, so the tetraphenylborate anion was used instead. The bond length C20-N21, 1.311(2) A, corresponds to a double bond and thus to a formal positive charge at the nitrogen atom. Similarly, C3-C4, at $1.342(2) \AA$, is also a (marginally lengthened) double bond. The $\mathrm{C}-\mathrm{S}$ bond lengths in the five-membered ring are approximately equal $[1.727(1)-1.746(1) \AA]$.

The new 1,3-dithiolium cations are particularly prone to nucleophilic attack at their 2-positions [30]. This behavior opens the way for the synthesis of various substituted 1,3-dithiolic rings, especially those with a 2-ylidene moiety resulting from a $C$-nucleophile attack. Furthermore, by using oxygen, sulfur, phosphorus, or nitrogen nucleophiles, interesting and novel structures can in principle be obtained [31]. The above combination of the chemistry of 1,3-dithiol-2-yl cations and the biological properties of flavonoids may provide new compounds with interesting properties.

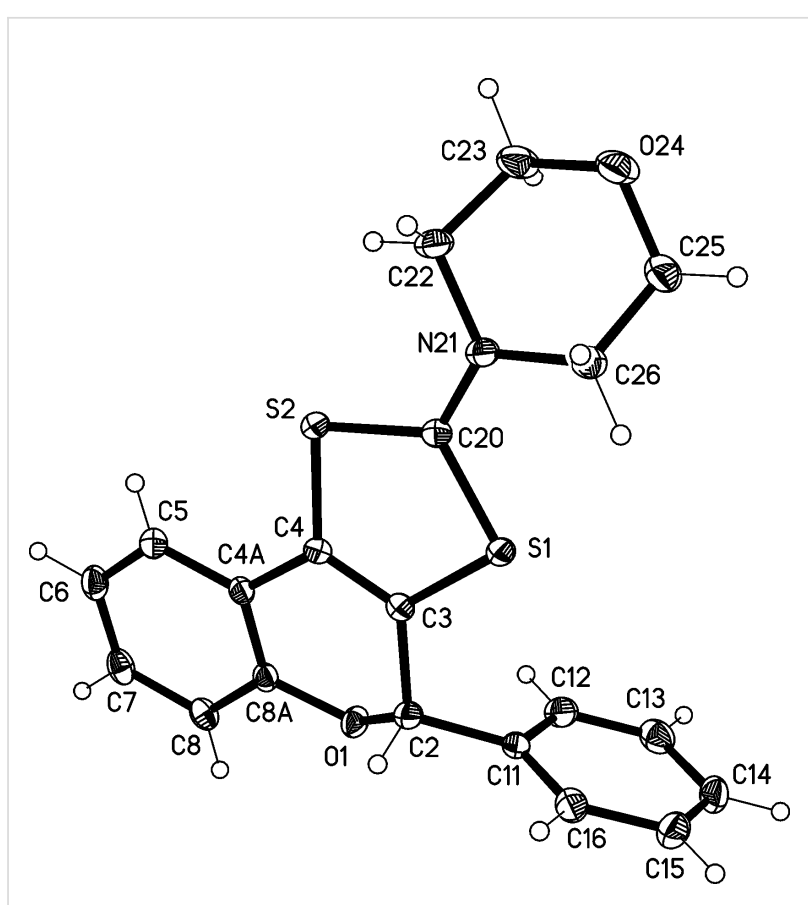

Figure 5: Molecular structure of flavonoid $\mathbf{7 a}$ in the solid state. Ellipsoids represent $50 \%$ probability levels.

\section{Conclusion}

The synthesis of 3-dithiocarbamic flavonoids has been accomplished by the reaction of the corresponding 2-hydroxyphenacyl dithiocarbamates with aminals. Under strongly acidic conditions these compounds provide novel tricyclic, fused flavonoids with a 1,3-dithiol-2-yl substructure. The reactivity of the latter derivatives could open the way for the synthesis of new flavonoids with potential biological activities.

\section{Supporting Information}

\section{Supporting Information File 1}

Experimental and X-ray spectral data.

[http://www.beilstein-journals.org/bjoc/content/ supplementary/1860-5397-8-226-S1.pdf]

\section{References}

1. Taylor, L. P.; Grotewold, E. Curr. Opin. Plant Biol. 2005, 8, 317-323. doi:10.1016/j.pbi.2005.03.005

2. Peer, W. A.; Murphy, A. S. Trends Plant Sci. 2007, 12, 556-563. doi:10.1016/j.tplants.2007.10.003

3. Buer, C. S.; Imin, N.; Djordjevic, M. A. J. Integr. Plant Biol. 2010, 52, 98-111. doi:10.1111/j.1744-7909.2010.00905.x

4. Jagtap, S.; Meganathan, K.; Wagh, V.; Winkler, J.; Hescheler, J.; Sachinidis, A. Curr. Med. Chem. 2009, 16, 1451-1462. doi:10.2174/092986709787909578 
5. Norman, B. H.; Dodge, J. A.; Richardson, T. I.; Borromeo, P. S.; Lugar, C. W.; Jones, S. A.; Chen, K.; Wang, Y.; Durst, G. L.; Barr, R. J.; Montrose-Rafizadeh, C.; Osborne, H. E.; Amos, R. M.; Guo, S.; Boodhoo, A.; Krishnan, V. J. Med. Chem. 2006, 49, 6155-6157. doi:10.1021/jm060491j

6. Richardson, T. I.; Norman, B. H.; Lugar, C. W.; Jones, S. A.; Wang, Y.; Durbin, J. D.; Krishnan, V.; Dodge, J. A. Bioorg. Med. Chem. Lett. 2007, 17, 3570-3574. doi:10.1016/j.bmcl.2007.04.051

7. Richardson, T. I.; Dodge, J. A.; Durst, G. L.; Pfeifer, L. A.; Shah, J.; Wang, Y.; Durbin, J. D.; Krishnan, V.; Norman, B. H. Bioorg. Med. Chem. Lett. 2007, 17, 4824-4828. doi:10.1016/j.bmcl.2007.06.052

8. Richardson, T. I.; Dodge, J. A.; Wang, Y.; Durbin, J. D.; Krishnan, V.; Norman, B. H. Bioorg. Med. Chem. Lett. 2007, 17, 5563-5566. doi:10.1016/j.bmcl.2007.08.009

9. Duke, J. A. Duke's Handbook of Medicinal Plants of Latin America; CRC Press: Boca Raton, 2009. doi:10.1201/9781420043174

10. Tang, W.; Eisenbrand, G. Handbook of Chinese Medicinal Plants: Chemistry Pharmacology Toxicology; Wiley-VCH: Weinheim, Germany, 2010; Vol. 1.

11. Hikino, H.; Taguchi, T.; Fujimura, H.; Hiramatsu, Y. Planta Med. 1977, 31, 214-220. doi:10.1055/s-0028-1097516

12. Moon, C. K.; Yun, Y. P.; Lee, J. H.; Wagner, H.; Shin, Y. S Planta Med. 1985, 51, 66-67. doi:10.1055/s-2007-969397

13. LaFemina, R. L.; Graham, P. L.; LeGrow, K.; Hastings, J. C.; Wolfe, A.; Young, S. D.; Emini, E. A.; Hazuda, D. J.

Antimicrob. Agents Chemother. 1995, 39, 320-324. doi:10.1128/AAC.39.2.320

14. Ishii, H.; Koyama, H.; Hagiwara, K.; Miura, T.; Xue, G.; Hashimoto, Y.; Kitahara, G.; Aida, Y.; Suzuki, M. Bioorg. Med. Chem. Lett. 2012, 22, 1469-1474. doi:10.1016/j.bmcl.2011.06.066

15. Schulzke, C. Dalton Trans. 2005, 713-720. doi:10.1039/b414853c

16. Birsa, M. L. Synth. Commun. 2002, 32, 115-118. doi:10.1081/SCC-120001517

17. Birsa, M. L. An. Stiint. Univ. "Al.I. Cuza" lasi 1998, 6, 57-64. Chem. Abstr. 2000, 132, $207785 z$.

18. Birsa, M. L. An. Stiint. Univ. "Al.I. Cuza” lasi 1999, 7, 349-354. Chem. Abstr. 2000, 134, 100788s.

19. Birsa, M. L. An. Stiint. Univ. "Al.I. Cuza" lasi 2000, 8, 329-334. Chem. Abstr. 2001, 136, 216676e.

20. Seliger, H.; Happ, E.; Cascaval, A.; Birsa, M. L.; Nicolaescu, T.; Poinescu, I.; Cojocariu, C. Eur. Polym. J. 1999, 35, 827-833. doi:10.1016/S0014-3057(98)00069-X

21. Seliger, H.; Cascaval, A.; Birsa, M. L. An. Stiint. Univ. "Al.I. Cuza” lasi 1997, 5, 129-137. Chem. Abstr. 2000, 132, 207732e.

22. Birsa, M. L.; Ganju, D. J. Phys. Org. Chem. 2003, 16, 207-212. doi:10.1002/poc.599

23. Birsa, M. L. Sulfur Lett. 2003, 26, 155-162. doi:10.1080/02786110310001593643

24. Goanta, M.; Ciobanu, A. S.; Birsa, A.; Asaftei, I. V.; Birsa, M. L. Acta Chem. lasi 2009, 17, 35-48. http://aci.chem.uaic.ro/aci-download-pdf-4UFh4VqKNcnuusipZ3WfjSS PW116Z9A3

25. Leaver, D.; Robertson, W. A. H.; McKinnon, D. M. J. Chem. Soc. 1962, 1504-1509.

26. Campaigne, E.; Jacobsen, N. W. J. Org. Chem. 1964, 29, 1703-1708. doi:10.1021/jo01030a010

27. Takamizawa, A.; Hirai, K. Chem. Pharm. Bull. 1969, 17, 1924-1930. doi:10.1248/cpb.17.1924
28. Birsa, M. L. Synth. Commun. 2001, 31, 1271-1275. doi:10.1081/SCC-100104016

29. Birsa, M. L.; Asaftei, L. V. Monatsh. Chem. 2008, 139, 1433-1438. doi:10.1007/s00706-008-0944-y

30. Prinzbach, H.; Futterer, E. Adv. Heterocycl. Chem. 1966, 7, 39-151. doi:10.1016/S0065-2725(08)60589-9

31. Birsa, M. L. Synth. Commun. 2003, 33, 3071-3076. doi:10.1081/SCC-120022483

\section{License and Terms}

This is an Open Access article under the terms of the Creative Commons Attribution License

(http://creativecommons.org/licenses/by/2.0), which permits unrestricted use, distribution, and reproduction in any medium, provided the original work is properly cited.

The license is subject to the Beilstein Journal of Organic Chemistry terms and conditions:

(http://www.beilstein-journals.org/bjoc)

The definitive version of this article is the electronic one which can be found at: doi: $10.3762 /$ bjoc. 8.226 